\title{
Mesiodistal Crown Diameter of Normal Occlusion and Different Malocclusion Groups for a Sample of Kurdish Population of Erbil City
}

\author{
Rawand J. Othman ${ }^{1 *}$, Jameel A. Alkhashan² \\ ${ }^{1}$ Department of Orthodontic, Khanzad Teaching Center, Ministry of Health, Erbil, Kurdistan Region, Iraq, ${ }^{2}$ Department of POP, Hawler Medical \\ University, Erbil, Kurdistan Region, Iraq
}

\section{${ }^{*}$ Corresponding author: Rawand J. Othman, Department of Orthodontic, Khanzad Teaching Center, Ministry of Health, Erbil, Kurdistan Region, Iraq. E-mail: rawandden@gmail. com}

Received: 12 August 2019 Accepted: 19 December 2019 Published: 30 June 2020

\section{DOI}

10.25156/pti.v10n1y2020.pp32-37

\section{A B S TRA C T}

It is essential to know the tooth crown size to provide accurate diagnosis and treatment planning to ensure the satisfactory outcome of orthodontic treatment. The aim of the present study was to measure and compare mesiodistal crown diameter of a Kurdish sample in Erbil city with normal and different classes of malocclusion. The mesiodistal tooth width was measured by an electronic digital caliper on a total of 150 ( 75 males and 75 females) orthodontic models of secondary school students of different occlusal relationships (Class I normal occlusion, Class I, Class II division I, Class II division II, and Class III malocclusions). The results showed that (1) the maxillary right first molar was significantly larger than the left one and both maxillary right lateral incisors and first premolars were larger than their contralateral teeth at the level of $P<0.01$. (2) Both upper and lower canine were significantly smaller in females than in males; (3) Class I malocclusion showed tendency toward larger teeth than the rest of the other occlusal categories; (4) no statistically significant differences in tooth size were found among the Class II division I, division II, and Class III malocclusions when compared to normal occlusion. In conclusion, females had smaller teeth than males and there was asymmetry between the right and left sides in tooth size and Class I malocclusion showed tendency toward larger teeth.

Keywords: Crown diameter; Mesiodistal crown width; Normal occlusion; Tooth size; Malocclusion

\section{INTRODUCTION}

The mesiodistal tooth width is correlated to the arch alignment and large teeth are associated with crowded dental arches and small teeth are associated with spaced dental arches (Bermudez de Castro and Nicolas, 1995). On a clinical level, mesiodistal tooth width has an anthropological significance because it provides valuable information on human evolution with its technological and dietary changes (Al-Khateeb and Abu Alhaija, 2006). Differences in tooth size have been associated with different ethnic backgrounds and malocclusions (Brook et al., 2014).

Tooth size exhibits a continuous range of variation among individuals and between populations (Mahmood, 2012). A comparative study between Jordanians, Iraqis, Yemenis, and Caucasians reported that Jordanians and Iraqis have larger teeth than the other populations and accumulated evidence indicates that tooth size reflects a complex interaction between a variety of genetic and environmental factors (Fernandes et al., 2013).
A proper relationship of the total mesiodistal width of the maxillary dentition to the mesiodistal width of the mandibular dentition will favor an optimal post-treatment occlusion (Santoro et al., 2000). The mesiodistal tooth width of the maxillary and mandibular arches must relate to each other to obtain an excellent occlusion at the completion of the orthodontic treatment (Bolton, 1958). Determination of tooth size ratio may predict the functional and esthetic outcome of the treatment (Heusdens et al., 2000).

Tooth size must be in harmony with arch size to allow proper alignment (Hashim and Al-Ghamdi, 2005). It was stated by Singh and Goyal (2006) that the task of the orthodontist is to align the teeth to improve the mastication efficiency, facial esthetics, and alignment of the dental arches, which becomes difficult in the presence of tooth size discrepancies.

An appropriate relationship of the mesiodistal widths of the maxillary and mandibular teeth favors a good post-treatment occlusion (Bernabe et al., 2004). Many factors such as heredity, growth of the bone, eruption 
and inclination of the teeth, external influences, function, and ethnic background can affect the size and the shape of the dental arches (Lavelle, 1972 and Bjork et al., 1984). It is important to have data concerning relevant human group for the purposes of clinical diagnosis and planning of treatment. The ethnic differences in tooth size and arch dimensions should be considered during treatment, especially in prosthodontics and orthodontics where arch shape can be modified appreciably (Burris and Harris, 2000).

There are many studies that have been conducted to investigate the mesiodistal crown dimension and relationships in different ethnicities and different geographical areas. Scant researches have been done on dental casts of the Kurdish population to determine the clinical significance of maxillary and mandibular tooth size measurements in orthodontic diagnosis and treatment planning. Therefore, the aim of the present study was compare the mesiodistal tooth diameter between the different occlusion groups. In addition, mesiodistal crown diameter compared between right and left sides and between genders in each groups.

\section{MATERIALS AND METHODS}

The study sample consisted from students in the secondary schools randomly selected with simple random sampling methods from different geographical areas within the area of Erbil city (north, south, east, and west). The examination was carried in 15 secondary schools, eight schools for males, and seven schools for females in 1 month period. The clinical examination included 4258 students, 2213 males and 2045 females.

The ethical approvals for conducting the study and sample selection were obtained from the ethical committee of research in College of Dentistry/Hawler Medical University. Permission has been taken from the school manager before starting the examination. Informed consent to participate and maintain confidentiality was observed. Before data collection researcher explained the objectives of this study to students and request consent for participation in the study.

The selected subjects were subjected to a thorough clinical examination to reassure the fulfillment of the required sample specifications, and then transported to specialized dental polyclinic for recoding case sheet, taking impressions, and lateral cephalometric X-rays. The following inclusion criteria were used:

1. Kurdish with Kurdish parents living in Erbil city

2. Complete permanent dentition excluding the second and third molars

3. All teeth are fully erupted to the occlusal plane.
While the exclusion criteria are as follows:

1. Large coronal restorations, buildups, crowns, onlays, and Class II restorations that affect a tooth's mesiodistal diameter

2. Congenital defects or deformed teeth and congenital missing teeth

3. Obvious interproximal or occlusal wear of teeth

4. The previous orthodontic treatment because of possibility of enamel interproximal reduction as a part of the treatment.

An electronic digital caliper (Hogetex, Germany) accurate up to $0.01 \mathrm{~mm}$ with sharp tips that facilitate accuracy was used to carry out all the measurements of the teeth Figure 1.

Out of 4258 Kurdish students, 200 subjects (100 males and 100 females) were chosen according to the criteria of the sample selection mentioned above with different groups (Class I normal occlusion, Class I malocclusion, Class II division I, Class II division II, and Class III malocclusions), then only 150 subjects were selected. Hence, finally, their distribution was: Thirty individuals for each group for both sex (15 males and 15 females) and the total number were 150 individuals.

The subjects in this study were classified to the different occlusion groups based on the categories of occlusion coincide with the skeletal categories. Occlusal relationships were classified according to Angle's classification (1899) of molar position in centric occlusion whereas the skeletal diagnosis was made on the basis of ANB angle values on lateral cephalometric using Al-Sahaf standards of Iraqi adults (Al-Sahaf, 1991).

Mesiodistal crown diameters of all teeth except second and third permanent molars were measured. The crown diameters were obtained by measuring the maximum

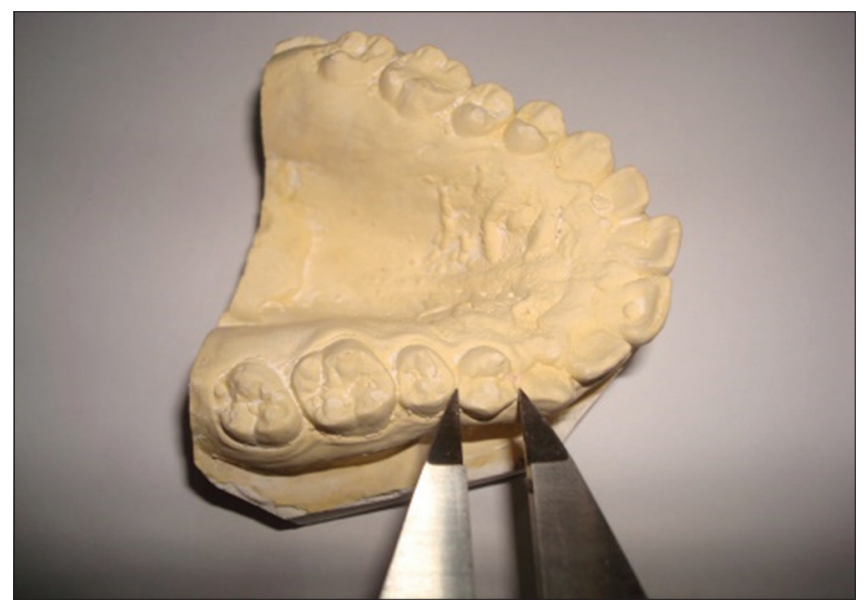

Figure 1: Example of mesiodistal width measurement 
distance between the mesial and distal contact points of the tooth. The measurements were made as carefully as possible to avoid any damage on beaks contact. The sharpened caliper beaks had been improving the access interproximally.

The caliper beaks were inserted and held occlusally parallel to the long axis of the tooth. The beaks were then closed until gentle contact with the tooth was felt. Starting the measurements from the maxillary right first permanent molar to the right central incisor on one side, crossing the mid line and measuring the left side to the other corresponding tooth, the same technique was used for measuring the mesiodistal crown diameter of the lower teeth.

Intra-examiner calibration carried out twice by the researcher, with time elapse of 2 weeks between the two measurements to overcome the memory bias, these are first reading and second reading then inter-examiner calibration, the same measurements carried out by well-trained dentist for the same models, this is the third reading and it is compared to the first reading.

T-value of intra-examiner and inter-examiner readings revealed non-significant differences between the mean values of all measurements.

\section{RESULTS AND DISCUSSION}

Statistical analysis revealed that the maxillary right first molar was significantly larger than the left one and both maxillary right lateral incisors and first premolars were larger than their contralateral teeth at the level of $P<0.01$. For the rest of the teeth, there was no significant difference between the right and the left sides, as shown in Table 1.

These findings are also in agreement with those reported in other population groups (Ngesa, 2003; Al-Khateeb and Abu Alhaija, 2006). The cause of this side similarity was attributed to a fact that, same factors on the same individual that affects the tooth size such as genetic, nutrition, and hormonal disturbances will affect its antimere (Maki et al., 2002; Gorjizadeh et al., 2015).

In this study, mesiodistal crown diameters comparison was conducted between male and female in Class I normal group and revealed that both upper and lower canine were significantly smaller in females than in males, as shown in Table 2. These findings are in agreement with Sanin and Savara, 1971; Hattab et al., 1996; Mossey et al., 1999; Hashim and Al-Ghamdi, 2005. Significant tooth size differences were found between males and females. The
Table 1: Comparison of the left and right mesiodistal crown diameter in the upper and lower dental arches

\begin{tabular}{|c|c|c|c|c|c|c|}
\hline \multirow[t]{2}{*}{ Tooth } & \multicolumn{2}{|c|}{ Right } & \multicolumn{2}{|c|}{ Left } & \multirow[t]{2}{*}{$t$-test } & \multirow[t]{2}{*}{$P$-value } \\
\hline & Mean & S.D. & Mean & S.D. & & \\
\hline \multicolumn{7}{|c|}{ Upper arch } \\
\hline 1 & 8.607 & 0.486 & 8.612 & 0.475 & 0.55 & 0.58 \\
\hline 2 & 6.673 & 0.493 & 6.651 & 0.488 & 2.91 & $0.004^{\star *}$ \\
\hline 3 & 7.707 & 0.454 & 7.711 & 0.469 & 0.28 & 0.777 \\
\hline 4 & 6.838 & 0.411 & 6.819 & 0.409 & 4.85 & $0.001^{* *}$ \\
\hline 5 & 6.54 & 0.463 & 6.507 & 0.411 & 1.49 & 0.139 \\
\hline 6 & 10.15 & 0.485 & 10.129 & 0.486 & 3.34 & $0.001^{* *}$ \\
\hline \multicolumn{7}{|c|}{ Lower arch } \\
\hline 1 & 5.433 & 0.313 & 5.437 & 0.349 & 0.31 & 0.76 \\
\hline 2 & 5.964 & 0.321 & 5.956 & 0.323 & 1.71 & 0.09 \\
\hline 3 & 6.785 & 0.431 & 6.801 & 0.43 & 0.95 & 0.34 \\
\hline 4 & 6.842 & 0.413 & 6.841 & 0.412 & 0.14 & 0.89 \\
\hline 5 & 6.93 & 0.444 & 6.936 & 0.445 & 0.96 & 0.34 \\
\hline 6 & 10.991 & 0.545 & 10.981 & 0.539 & 1.26 & 0.21 \\
\hline
\end{tabular}

**Highly significant at $P<0.01$ N.B: All measurements are in $\mathrm{mm}$

Table 2: Comparison between males and females of mesiodistal crown diameter in the upper and lower dental arches in Class I normal group

\begin{tabular}{|c|c|c|c|c|c|c|}
\hline \multirow[t]{2}{*}{ Tooth } & \multicolumn{2}{|c|}{ Male } & \multicolumn{2}{|c|}{ Female } & \multirow[t]{2}{*}{$t$-test } & \multirow[t]{2}{*}{$P$-value } \\
\hline & Mean & S.D. & Mean & S.D. & & \\
\hline \multicolumn{7}{|c|}{ Upper arch } \\
\hline 1 & 8.78 & 0.43 & 8.54 & 0.66 & 1.21 & 0.23 \\
\hline 2 & 6.82 & 0.47 & 6.52 & 0.59 & 1.54 & 0.14 \\
\hline 3 & 7.76 & 0.44 & 7.50 & 0.34 & 1.98 & $0.049^{*}$ \\
\hline 4 & 6.87 & 0.41 & 6.82 & 0.56 & 0.31 & 0.76 \\
\hline 5 & 6.50 & 0.39 & 6.41 & 0.36 & 0.67 & 0.51 \\
\hline 6 & 10.22 & 0.47 & 10.02 & 0.45 & 1.19 & 0.24 \\
\hline \multicolumn{7}{|c|}{ Lower arch } \\
\hline 1 & 5.44 & 0.23 & 5.35 & 0.34 & 0.80 & 0.43 \\
\hline 2 & 6.02 & 0.26 & 5.84 & 0.30 & 1.75 & 0.09 \\
\hline 3 & 6.97 & 0.39 & 6.61 & 0.32 & 2.73 & $0.01^{*}$ \\
\hline 4 & 6.76 & 0.34 & 6.80 & 0.45 & 0.47 & 0.64 \\
\hline 5 & 6.86 & 0.45 & 6.82 & 0.41 & 0.21 & 0.83 \\
\hline 6 & 10.96 & 0.61 & 10.97 & 0.52 & 0.02 & 0.98 \\
\hline
\end{tabular}

*Significant at $P<0.05$.

results indicate the presence of sexual dimorphism, most teeth in male possessed a higher mean values than those of females, although not all the teeth show a significant difference between the two genders. This comes in accordance with Ghose and Baghdady, 1979; Al-Rashdan, 1996; Hattab et al., 1996; Ngesa, 2003; Al-Khateeb and Abu Haija, 2006. The exact reason laying behind this difference is not well understood. However, sex-linked inheritance and sex-hormonal influences were suggested (Alam et al., 2014).

One-way analysis of mean variance (ANOVA) test in Table 3 showed that the differences in mesiodistal crown diameter between the different classes are shown in Table 3 using one-way ANOVA. 
In the maxilla, no significant differences were observed between the means of all teeth width except the canine width that shows a highly significant difference $(P<0.01)$. In the mandible the central incisor shows a high significant differences $(P<0.01)$, and both lateral incisor and second premolar having significant means difference of tooth width $(P<0.05)$.

The least significant difference (LSD) test in Table 4 investigates the significance which result from ANOVA table and pinpoint the differences of means between each two groups of the skeletal classes as in that the Class I malocclusion groups exhibited larger mesiodistal crown diameter in the most lower and upper teeth than other classes; they were the greatest for mandibular incisor teeth and same findings were reported in some previous studies that found the mesiodistal crown diameter of the teeth to be significantly greater in Class I malocclusion subjects with dental crowding as compared to subjects with normal occlusion (e.g., Wedrychowska-Szulc et al., 2010; Nawar et al., 2014).

The LSD table shows a significant difference in means of the mesiodistal crown diameter of the upper teeth except (second premolar and first molar) and the lower teeth except (first and second premolar) when Class I malocclusion compared to Class II division II.

The current findings were consistent with those of Agenter et al. (2009) who found significantly smaller crown

Table 3: ANOVA table for the tooth width means' differences between all classes

\begin{tabular}{|c|c|c|c|c|c|c|c|c|c|c|c|c|}
\hline \multirow[t]{2}{*}{ Tooth } & \multicolumn{2}{|c|}{ Class I normal } & \multicolumn{2}{|c|}{ Class I Mal } & \multicolumn{2}{|c|}{ Class II Div I } & \multicolumn{2}{|c|}{ Class II Div.II } & \multicolumn{2}{|c|}{ Class III } & \multirow[t]{2}{*}{ F-test } & \multirow[t]{2}{*}{$P$-value } \\
\hline & Mean & S.D. & Mean & S.D. & Mean & S.D. & Mean & S.D. & Mean & S.D. & & \\
\hline \multicolumn{13}{|c|}{ Upper arch } \\
\hline 1 & 8.66 & 0.56 & 8.72 & 0.50 & 8.67 & 0.52 & 8.42 & 0.36 & 8.58 & 0.39 & 1.89 & 0.116 \\
\hline 2 & 6.67 & 0.54 & 6.80 & 0.40 & 6.64 & 0.65 & 6.52 & 0.40 & 6.69 & 0.37 & 1.29 & 0.276 \\
\hline 3 & 7.63 & 0.41 & 7.89 & 0.41 & 7.84 & 0.54 & 7.47 & 0.43 & 7.72 & 0.37 & 4.48 & $0.002^{* *}$ \\
\hline 4 & 6.85 & 0.48 & 6.97 & 0.43 & 6.84 & 0.44 & 6.75 & 0.32 & 6.73 & 0.34 & 1.62 & 0.172 \\
\hline 5 & 6.45 & 0.37 & 6.67 & 0.43 & 6.56 & 0.50 & 6.47 & 0.37 & 6.46 & 0.37 & 1.50 & 0.204 \\
\hline 6 & 10.12 & 0.46 & 10.28 & 0.62 & 10.21 & 0.48 & 10.13 & 0.43 & 9.96 & 0.38 & 1.87 & 0.119 \\
\hline \multicolumn{13}{|c|}{ Lower arch } \\
\hline 1 & 5.39 & 0.29 & 5.62 & 0.37 & 5.50 & 0.26 & 5.35 & 0.33 & 5.30 & 0.27 & 5.19 & $0.001^{* *}$ \\
\hline 2 & 5.93 & 0.29 & 6.12 & 0.29 & 6.01 & 0.29 & 5.89 & 0.34 & 5.85 & 0.33 & 3.47 & $0.010^{*}$ \\
\hline 3 & 6.79 & 0.40 & 6.96 & 0.40 & 6.83 & 0.57 & 6.68 & 0.31 & 6.74 & 0.40 & 1.88 & 0.118 \\
\hline 4 & 6.80 & 0.40 & 7.01 & 0.43 & 6.83 & 0.50 & 6.80 & 0.32 & 6.77 & 0.38 & 1.63 & 0.169 \\
\hline 5 & 6.84 & 0.42 & 7.11 & 0.45 & 7.01 & 0.48 & 6.92 & 0.36 & 6.78 & 0.44 & 2.93 & $0.023^{*}$ \\
\hline 6 & 10.96 & 0.55 & 11.21 & 0.52 & 10.93 & 0.60 & 10.83 & 0.47 & 11.01 & 0.50 & 2.11 & 0.082 \\
\hline
\end{tabular}

${ }^{*}$ Significant at $P<0.05$. ${ }^{* *}$ Highly significant at $P<0.01$. N.B: All measurements are in $\mathrm{mm}$

Table 4: LSD after ANOVA of tooth width for all different classes

\begin{tabular}{|c|c|c|c|c|c|c|c|c|c|c|}
\hline \multirow[t]{2}{*}{ Tooth } & $\begin{array}{c}\text { Class I } \\
\text { normal } \\
\text { and Class } \\
\text { I Mal. }\end{array}$ & $\begin{array}{c}\text { Class I } \\
\text { Normal and } \\
\text { Class II Div. I }\end{array}$ & $\begin{array}{c}\text { Class I } \\
\text { Normal and } \\
\text { Class II Div.II }\end{array}$ & $\begin{array}{c}\text { Class I } \\
\text { Normal and } \\
\text { Class III }\end{array}$ & $\begin{array}{l}\text { Class I } \\
\text { Mal. and } \\
\text { Class II } \\
\text { Div. I }\end{array}$ & $\begin{array}{l}\text { Class I } \\
\text { Mal. and } \\
\text { Class II } \\
\text { Div.II }\end{array}$ & $\begin{array}{l}\text { Class I } \\
\text { Mal and } \\
\text { Class III }\end{array}$ & $\begin{array}{l}\text { Class II } \\
\text { Div.I and } \\
\text { Class II } \\
\text { Div.II }\end{array}$ & $\begin{array}{l}\text { Class II } \\
\text { Div. I and } \\
\text { Class III }\end{array}$ & $\begin{array}{c}\text { Class II } \\
\text { Div. II and } \\
\text { Class III }\end{array}$ \\
\hline & $P$-value & $P$-value & $P$-value & $P$-value & $P$-value & $P$-value & $P$-value & $P$-value & $P$-value & $P$-value \\
\hline \multicolumn{11}{|c|}{ Upper arch } \\
\hline 1 & 0.61 & 0.95 & 0.051 & 0.49 & 0.65 & $0.014^{*}$ & 0.61 & $0.043^{*}$ & 0.45 & 0.2 \\
\hline 2 & 0.29 & 0.82 & 0.25 & 0.86 & 0.2 & $0.027^{*}$ & 0.37 & 0.34 & 0.96 & 0.18 \\
\hline 3 & $0.019^{*}$ & 0.29 & 0.17 & 0.44 & 0.6 & $0.000^{*}$ & 0.11 & $0.002^{*}$ & 0.29 & $0.032^{*}$ \\
\hline 4 & 0.24 & 0.97 & 0.37 & 0.28 & 0.22 & $0.04^{*}$ & $0.025^{\star}$ & 0.4 & 0.3 & 0.84 \\
\hline 5 & $0.044^{*}$ & 0.33 & 0.85 & 0.95 & 0.3 & 0.07 & 0.051 & 0.425 & 0.36 & 0.9 \\
\hline 6 & 0.2 & 0.45 & 0.93 & 0.2 & 0.61 & 0.24 & $0.011^{*}$ & 0.5 & $0.042^{*}$ & 0.17 \\
\hline \multicolumn{11}{|c|}{ Lower arch } \\
\hline 1 & $0.005^{* *}$ & 0.17 & 0.61 & 0.26 & 0.14 & $0.001^{\star *}$ & $0.000^{\star *}$ & 0.061 & $0.013^{*}$ & 0.53 \\
\hline 2 & $0.019^{*}$ & 0.28 & 0.69 & 0.35 & 0.2 & $0.006^{\star *}$ & $0.001^{\star *}$ & 0.14 & $0.04^{\star}$ & 0.59 \\
\hline 3 & 0.12 & 0.69 & 0.31 & 0.67 & 0.25 & $0.01^{*}$ & $0.05^{\star}$ & 0.16 & 0.41 & 0.28 \\
\hline 4 & $0.05^{*}$ & 0.73 & 0.97 & 0.83 & 0.09 & 0.051 & $0.03^{*}$ & 0.76 & 0.57 & 0.79 \\
\hline 5 & $0.02^{*}$ & 0.12 & 0.46 & 0.56 & 0.37 & 0.09 & $0.003^{\star *}$ & 0.41 & $0.03^{*}$ & 0.19 \\
\hline 6 & 0.08 & 0.78 & 0.31 & 0.76 & $0.04^{*}$ & $0.006^{\star *}$ & 0.14 & 0.46 & 0.56 & 0.19 \\
\hline
\end{tabular}

*Significant at $P<0.05$. ${ }^{*}$ Highly Significant at $P<0.01$. N.B: All measurements are in $\mathrm{mm}$ 
dimensions in their group with naturally-occurring normal occlusion, suggesting that mesiodistal crown diameter is a risk factor for malocclusion so the clinical solution is to reduce mesiodistal crown diameter either by slicing or extraction.

While the findings for the Class II division II revealed that there was a tendency of having smaller teeth when compared to normal occlusion but not reach a significant level, while it is showed a significantly smaller maxillary canine when compared to the other malocclusion groups; hence, the finding of the current study is in agreement with Peck et al. (1998) that pointed to systematically reduced tooth size as a trait associated with Class II division II malocclusion.

It is not possible to attribute a characteristic pattern of mesiodistal dimensions to the different manifestations of incisor retroclination in Class II Division II malocclusion (Mariano et al., 2013).

Finally, the LSD test investigated the non-significance difference for mesiodistal crown diameter of all teeth in Class I normal compared to Class II division I, division II and Class III malocclusions and this is agreed with AlKhateeb and Abu Alhaija, (2006).

\section{CONCLUSIONS}

Based on the findings, it can be concluded that there were differences in mesiodistal crown diameter between right and left sides confirming the presence of asymmetry between the two sides and males showed a tendency toward larger mesiodistal crown diameter than that of females but not all of them reach a significant level. While a Class I malocclusion showed a tendency toward larger teeth than the other occlusal categories, especially for lower anterior teeth and no statistically significant differences in tooth size were found in the Class II division I, division II and Class III malocclusions when compared to normal occlusion.

Further, research recommended assessing the anterior and overall Bolton ratios in the normal and different malocclusions in a Kurdish sample.

\section{REFERENCES}

Agenter, M. K., E. F. Harris and R. N. Blair. 2009. Influence of tooth crown size on malocclusion. Am. J. Orthod. Dentofacial. Orthop. 136(6): 795-804.

Alam, M. K., F. Shahid, K. Purmal, B. Ahmad and M. F. Khamis. 2014. Tooth size and dental arch dimension measurement through cone beam computed tomography: Effect of age and gender. Res. J. Recent Sci. 3: 85-94.
Al-Khateeb, S. N. and E. S. J. Abu Alhaija. 2006. Tooth size discrepancies and arch parameters among different malocclusions in a Jordanian sample. Angle Orthod. 76: 459-465.

Al-Rashdan, M. S. 1996. Odontometric Study of Maxillary and Mandibular Permanent Teeth in Relation to Each Dimension in Iraqi Sample. Baghdad University, Iraq.

Al-Sahaf, N. H. 1991. Cross Sectional Study of Cephalometric Standards and Associated Growth Changes. Master Thesis, College of Dentistry. Baghdad University, Iraq.

Angle, E. H. 1899. Classification of malocclusion. Dent. Cosm. 41(18): 284-264.

Bermudez de Castro, J. M. and M. E. Nicolas. 1995. Posterior dental size reduction in hominids: The Atapuerca evidence. Am. J. Phys. Anthropol. 96: 335-356.

Bernabe, E., C. Flores-Mir and P. W. Major. 2004. Tooth width ratio discrepancies in a sample of Peruvian adolescents. Am. J. Orthod. Dentofacial. Orthop. 125(3): 361-365.

Bjork, A., T. Brown and V. Skieller. 1984. Comparison of craniofacia growth in Australian Aboriginal and Danes, illustrated by longitudinal cephalometric analysis. Eur. J. Orthod. 6: 1-14.

Bolton, W. 1958. Disharmony in tooth size and its relation to the analysis and treatment of malocclusion. Angle Orthod. 28(3): 113-130.

Brook, A. H., J. Jernvall, R. N. Smith, T. E. Hughes and G. C. Townsend. 2014. The dentition: The outcomes of morphogenesis leading to variations of tooth number, size and shape. Aust. Dent. J. 59: 131-142.

Burris, B. G. and F. H. Harris. 2000. Maxillary arch size and shape in american blacks and whites. Angle Orthod. 70: 297-302.

Fernandes, T. M., R. Sathler, G. L. Natalício, J. F. Henriques and A. Pinzan. 2013. Comparison of mesiodistal tooth widths in Caucasian, African and Japanese individuals with Brazilian ancestry and normal occlusion. Dent. Press J. Orthod. 18: 130-135.

Ghose, L. and V. Baghdady. 1979. Analysis of the Iraqi dentition: Mesiodistal crown diameters of permanent teeth. J. Dent. Res. 58: 1047-1054.

Gorjizadeh, F., M. M. Javaheri and A. R. Maktabi. 2015. Analyzing mesiodistal widths of the permanent teeth. Iran. J. Orthop. 10: e4984.

Hashim, H. A. and S. A. F. Al-Ghamdi. 2005. Tooth width and arch dimension in normal and malocclusion samples. An odontometric study. J. Contemp. Dent. Pract. 2: 36-51.

Hattab, F. N., S. Al-Khateeb and I. Sultan. 1996. Mesiodistal crown diameter of permanent teeth in Jordanians. Arch. Oral Biol. 41: 641-645.

Heusdens, M., L. Dermaut and R. Verbeeck. 2000. The effect of tooth size discrepancy on occlusion: An experimental study. Am. J. Orthod. Dentofacial. Orthop. 117: 184-191.

Lavelle, C. L. 1972. Maxillary and mandibular tooth size in different racial group and in different occlusal categories. Am. J. Orthod. 61: 29-37.

Mahmood, A. D. 2012. A comparative study of tooth size and dental arch dimensions between Iraqi Arabs and Kurds with class I normal occlusion. Al-Rafidain Dent. J. 12: 71-79.

Maki, K., T. Nishioka, E. Shioiri, T. Takahashi and M. Kimura. 2002. Effects of dietary consistency on the mandible of rats at the growth stage: Computed X-ray densitometric and cephalometric analysis. Angle Orthod. 72(5): 468-475.

Mariano, P. P., A. P. Ferreira, P. Tavares and A. C. Braga. 2013. Different manifestations of Class II Division 2 incisor retroclination: A morphologic study. Am. J. Orthod. Dentofacial. 
Orthop. 143(3): 310-316.

Mossey, P. A. 1999. The heritability of malocclusion: Part 1-Genetics principles and terminology. Br. J. Orthod. 26: 1113.

Nawar, A. G. and D. J. Al-Dabagh. 2014. Mesio-distal crown dimension of permanent dentition in normal, crowding, and spacing of young adult sample aged 18-25 years. J. Baghdad Coll. Dent. 26(4): 180-186.

Ngesa, J. L. 2003. Applicability of Tooth Size Predictions in the Mixed Dentition Analysis in a Kenyan Sample, Master Mini Thesis. University of the Western Cape, South Africa.

Peck, S., L. Peck and M. Kataja. 1998. Class II division 2 malocclusion: A heritable pattern of small teeth in well-developed Jaws. Angle
Orthod. 1: 9-20.

Sanin, C. and B. S. Savara. 1971. An analysis of permanent mesiodistal crown size. Am. J. Orthod. 59(5): 488-500.

Santoro, M., M. Ayoub, V. Pardi and T. Cangialosi. 2000. Mesio-dista crown dimensions and tooth size discrepancy of the permanent dentition of Dominican Americans. Angle Orthod. 70: 303-307.

Singh, S.P. and A. Goyal. 2006. Mesiodistal crown dimensions of the permanent dentition in North Indian children. Angle Orthod. 41: 293-299.

Wedrychowska-Szulc, B., J. Janiszewska-Olszowska and P. Stepien. 2010. Overall and anterior Bolton ratio in Class I, II, and III orthodontic patients. Eur. J. Orthod. 32: 313-318. 